\title{
A woman with one red ear
}

\author{
Fumitaka Yoshimura ${ }^{1}$ \\ ${ }^{1}$ Yushima clinic
}

February 3, 2022

\begin{abstract}
When redness of the auricle is present, the main differential diagnoses are erysipelas, Ramsay-Hunt syndrome, relapsing polychondritis, and chilblain lupus. The pathogenesis of red ears can be inferred by careful anatomical observation. Making the correct diagnosis is important because the treatment and prognosis vary according to the cause.
\end{abstract}

Clinical Image

A woman with one red ear

[Authors] Fumitaka Yoshimura

[Affiliations] Department of Internal Medicine, Yushima Clinic, 655, Yushima, Oyano, Kamiamakusa, Kumamoto, 869-3711, Japan

Correspondence to: Fumitaka Yoshimura

\section{Consent for publication:}

Written informed consent was obtained from the patient to publish this report in accordance with the journal's patient consent policy

A 62-year-old woman visited our clinic due to redness of the right ear since the previous day (Figure 1). Physical examination revealed a slight fever $\left(37.6^{\circ} \mathrm{C}\right)$, chills, and heat and tenderness on her right ear and preauricular area. There were no blisters on, in or around the ear. Otoscopy showed no abnormalities of the external auditory canal or tympanic membrane. Blood tests showed an elevated white blood cell count $(11,600$ cells $/ \mu \mathrm{L})$. Therefore, unilateral ear erysipelas was diagnosed. After intravenous amoxicillin for 7 days, the redness on the right ear and preauricular area disappeared.

When redness of the auricle is present, the main differential diagnoses are erysipelas, Ramsay-Hunt syndrome, relapsing polychondritis, and chilblain lupus. In order to differentiate between them, it is necessary to ascertain whether the redness is unilateral or bilateral, and whether blisters, or tenderness are present.

The auricle has no deeper dermis and subcutaneous tissue. As the inflammation involved epidermis and superficial lymphatics, the lesion was diagnosed as erysipelas rather than cellulitis. The feature is called Milian's ear sign [1]. The pathogenesis of red ears can be inferred by careful anatomical observation. Making the correct diagnosis is important because the treatment and prognosis vary according to the cause.

Reference

[1] Madke B, Nayak C. Eponymous signs in dermatology. Indian Dermatol Online J. 2012 Sep; 3(3): 159-165. 


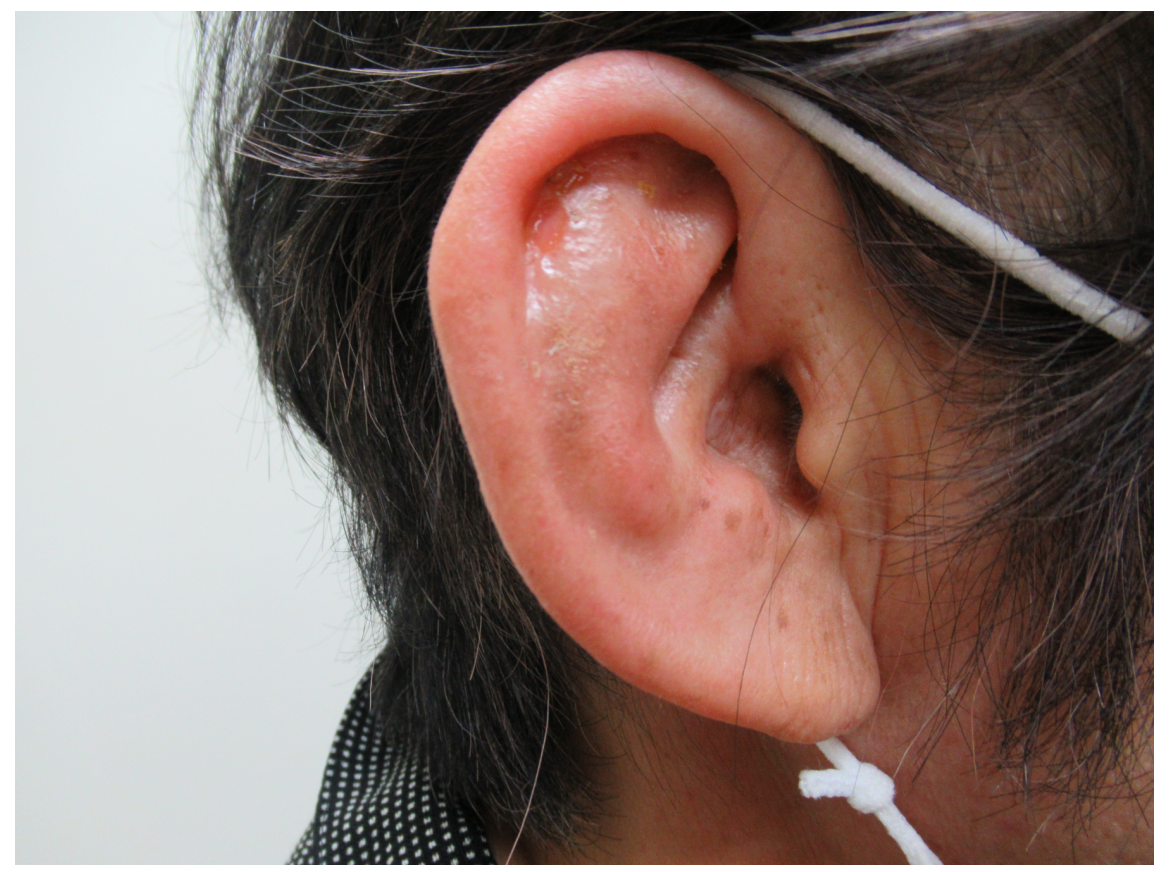

